\title{
Mucoepidermoid Carcinoma Arising in a Background of Sialadenoma Papilliferum: A Case Report
}

\author{
Wei Liu · Douglas R. Gnepp · Egbert de Vries · \\ Haidy Bibawy $\cdot$ Marshall Solomon . \\ Elizabeth S. Gloster
}

Received: 9 December 2008/ Accepted: 29 January 2009/Published online: 15 February 2009

(C) Humana 2009

\begin{abstract}
Sialadenoma papilliferum is a rare tumor, primarily of minor salivary gland origin, first described by Abrams and Finck (Cancer 24:1057-63, 1969). It is both an exophytic and endophytic papillary lesion histologically resembling syringocystadenoma papilliferum of sweat gland. The tumor is considered benign although rare recurrent cases have been reported. Three cases of malignant transformation of sialadenoma papilliferum have been described in the literature. We report a high grade mucoepidermoid carcinoma arising in a background of sialadenoma papilliferum, at the base of the tongue, an unusual location for minor salivary gland neoplasms. Eleven months after excision and nodal dissection, there is no evidence of recurrence or metastasis.
\end{abstract}

Keywords Sialadenoma papilliferum ·

Mucoepidermoid carcinoma $\cdot$ Salivary gland

\section{Introduction}

Sialadenoma papilliferum is a rare tumor of minor salivary gland origin, first described by Abrams and Finck in 1969

W. Liu $(\bowtie) \cdot$ M. Solomon · E. S. Gloster

Departments of Pathology, SUNY Downstate Medical Center,

450, Clarkson Avenue, Brooklyn, NY 11203, USA

e-mail:wliu30@gmail.com

D. R. Gnepp

Department of Pathology, Albert School of Medicine at Brown University, Rhode Island Hospital, 593 Eddy Street, Providence, RI 02903, USA

E. de Vries · H. Bibawy

Department of Otolaryngology, SUNY Downstate Medical

Center, 450, Clarkson Avenue, Brooklyn, NY 11203, USA
[1]. It is both an exophytic and endophytic papillary lesion histologically resembling syringocystadenoma papilliferum of sweat gland. The tumor is considered benign although rare recurrent cases have been reported $[2,3]$. Three cases of malignant transformation of sialadenoma papilliferum have been described in the literature [4-6]. We report a fourth case, a high grade mucoepidermoid carcinoma arising in a background of sialadenoma papilliferum, at the base of the tongue, an unusual location for minor salivary gland neoplasms.

\section{Case Report}

An 82-year-old female with medical history of diabetes mellitus and hypertension presented with a 3-month history of dysphagia secondary to a $2-\mathrm{cm}$ papillary, exophytic mass at the left base of the tongue. This tumor ultimately was interpreted as a high grade mucoepidermoid carcinoma arising in a background of a sialadenoma papilliferum. The patient subsequently underwent tumor excision and followup margin excision with level II, III and IV left neck lymph node dissection. No residual tumor was identified and four lymph nodes were negative for tumor. All specimens were negative for microvascular invasion. The patient was discharged. She was regularly followed-up and no recurrence of the tumor was documented eleven months after the surgery.

Microscopically, the lesion demonstrates prominent papillarity that in some areas, appears to be centered around an excretory minor salivary gland duct. The opening of the duct is in direct continuity with the stratified acanthotic squamous epithelium covering the papillary areas of the tumor (Fig. 1a, b). Most of the ductal epithelium is bi-layered or stratified with tall columnar cells in 
the luminal layer and short, cuboidal cells in the basal layer. Scattered goblet cells and ciliated metaplastic cells are interspersed. Extensive squamous metaplasia is present focally. The papillary fronds of the tumor, which are supported by fibrovascular cores, protrude into the ductal space. Lymphocytic and plasmacytic inflammation is present in the cores. The above described lesion was interpreted as sialadenoma papilliferum.

The deeper and malignant portion of the tumor grows in a more solid pattern with well defined squamous differentiation (Figs. 1c, 2a, b), intermediate cells, and nests of gland-like structures. Scattered foci demonstrate definitive mucin-positive tumor cells (confirmed by mucicarmine stain, Sigma-Aldrich, St. Louis, MO) (Fig. 2c), which are focally intermixed with the squamous component. Nuclear pleomorphism, hyperchromasia, and high mitotic activity are evident in the squamous component, which is in close association with adjacent salivary ductal epithelium, and with the deeper portion of sialadenoma papilliferum (Fig. 2a). In many areas, the malignant tumor obliterates the benign lesion and infiltrates beyond the confines of the sialadenoma papilliferum. However, the sialadenoma papilliferum component retains its papillary and proliferative configuration, mostly at the surface (Fig. 2a). Our diagnosis was therefore high grade (Brandwein grading system) mucoepidermoid carcinoma arising in a background of sialadenoma papilliferum [7]. The followup re-excision and nodal dissection specimens showed only squamous metaplasia of minor salivary glands, and mucosal ulceration.

\section{Discussion}

Sialadenoma papilliferum usually occurs in older males in sites that have minor salivary glands, such as palate, buccal mucosa, retromolar pads and lips [8]. The base of tongue location, as in our case, has not been documented previously, although minor salivary glands are found in this location. The proliferative, dilated salivary gland ducts with papillary fronds protruding into the lumen, together with the hyperplastic, hyperkeratotic overlying squamous epithelium, led us to the observation that there is a component of sialadenoma papilliferum, continuous with a deeper high grade mucoepidermoid carcinoma.

The true origin and nature of sialadenoma papilliferum have been controversial. The authors who first described this lesion believed it arises from myoepithelial cells [1]; while others have proposed that it is a result of focal hyperplasia following blockage of a salivary gland duct [9].
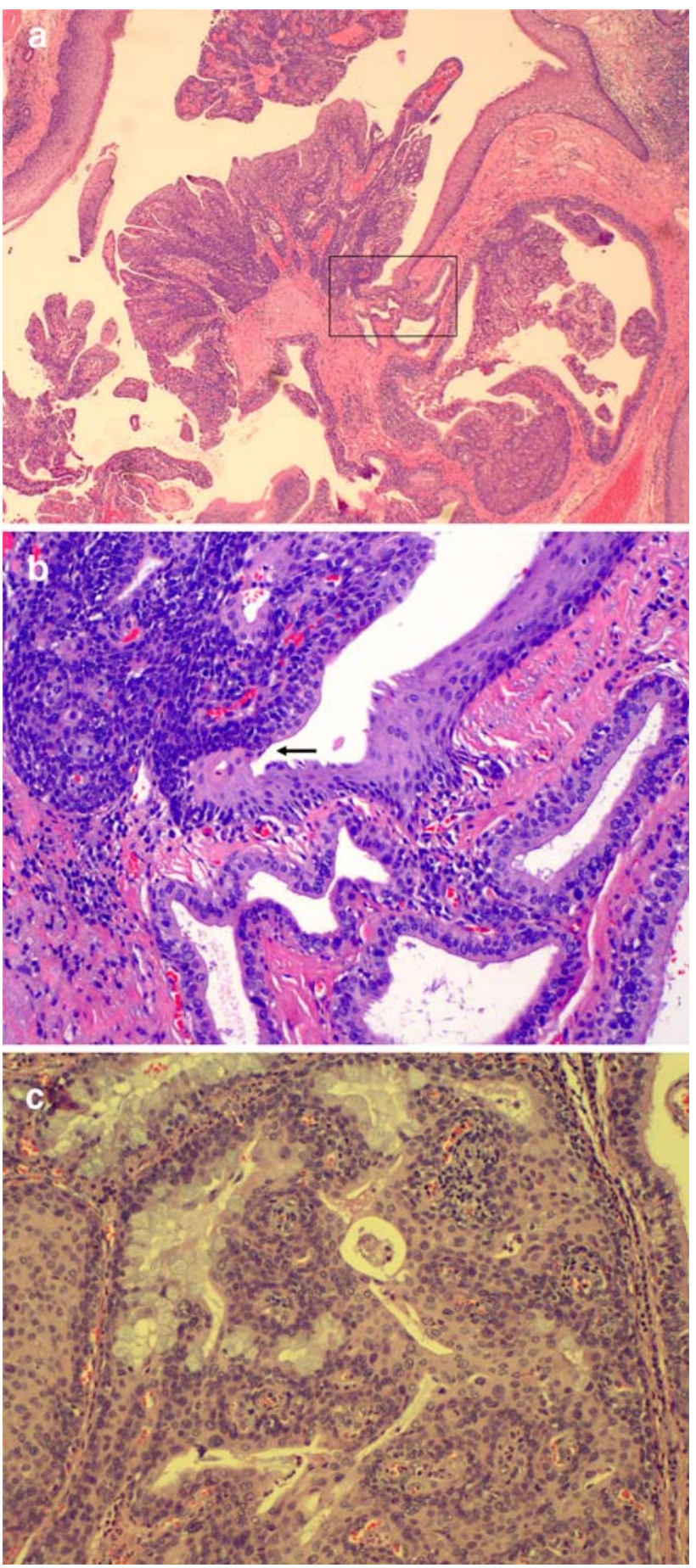

Fig. 1 a Sialadenoma papilliferum. Exophytic portion. $20 \times$; hemotoxylin-eosin stain. Boxed area is shown in higher magnification in illustration b. b Excretory salivary duct in direct connection with squamous epithelium. Arrow indicates the connection between squamous surface epithelium and salivary excretory duct columnar epithelium. 200x; hemotoxylin-eosin stain. c Mucoepidermoid carcinoma with intermixed components of squamoid, mucous and intermediate cells. $200 \times$; hemotoxylin-eosin stain 

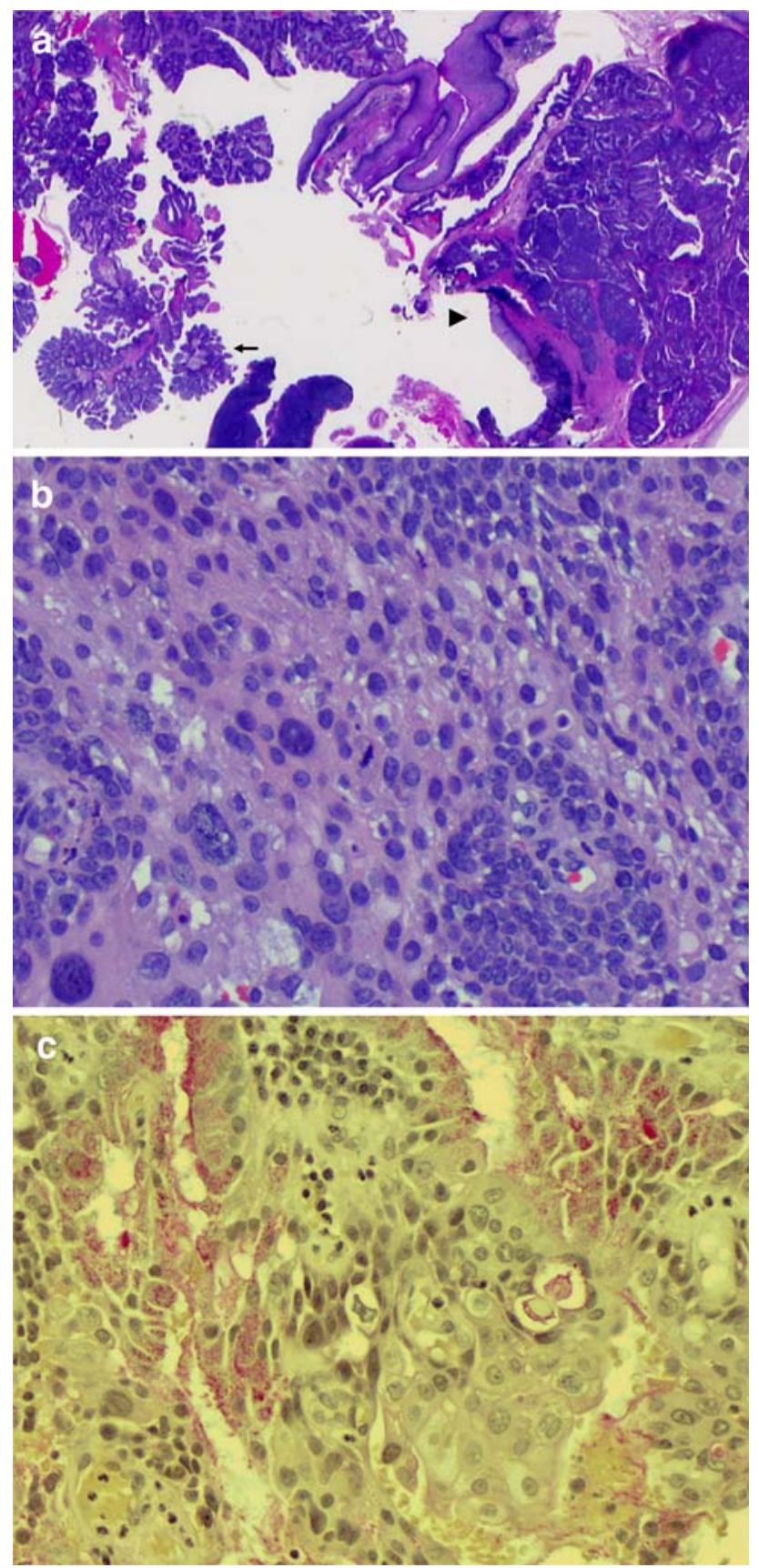

Fig. 2 a Mucoepidermoid carcinoma arising in a background of sialadenoma papilliferum. Arrow, superficial component of sialadenoma papilliferum. Arrowhead, deep portion of the lesion with mucoepidermoid carcinoma intermixed with sialadenoma papilliferum. $10 \times$, hemotoxylin-eosin stain. b Mucoepidermoid carcinoma. Predominantly squamous component with high grade nuclear features. 400×; hemotoxylin-eosin stain. c Mucicarmine stain for mucoepidermoid carcinoma, demonstrating both intraglandular and intracellular mucin. 400×; Mucicarmine stain (Sigma-Aldrich, St. Louis, MO)

The presence of ciliated cells in the lining epithelium of the duct in our case is consistent with the possibly metaplastic, reactive nature of sialadenoma papilliferum [10]. Most recently, it was reported that sialadenoma papilliferum is a neoplasm that originates from ductal surface cells [11].

Mucoepidermoid carcinoma sometimes is seen proliferating from a terminal salivary duct, supporting the concept that the tumor may originate from cells of the salivary gland excretory and intercalated ducts [12]. Although mucoepidermoid carcinoma can be associated with a large excretory salivary duct, a papillary, proliferating ductal lesion, as in this case, is not a feature. Chen [13] reported a case of intraductal low grade mucoepidermoid carcinoma occurring in minor salivary gland. The lesion was lobulated and composed of cystic ducts filled with tumor, which differs from the surface papillary configuration of a sialadenoma papilliferum.

Considering the papillary architecture of the lesion, our differential diagnosis consists of (1) a sialadenoma papilliferum with a papillary squamous cell carcinoma, (2) an adenosquamous carcinoma with prominent papillary features, (3) papillary squamous cell carcinoma, and (4) a papillary cystadenocarcinoma. Papillary squamous cell carcinoma is a distinct variant of squamous cell carcinoma characterized by an exophytic, papillary growth, which can resemble sialadenoma papilliferum in its gross appearance [14]. However, a glandular component with mucin-secreting cells is not present in this lesion. Adenosquamous carcinoma has distinctively separate components of adenoand squamous differentiation with no papillary configuration [14]. Cystadenocarcinoma is a rare malignant tumor characterized by predominantly cystic growth and conceptually it is the malignant counterpart of the benign cystadenoma. It does not include squamous elements [14]. Distinctively squamous differentiation is not a feature of papillary cystadenocarcinoma. Cell types that comprise the lining epithelium of cysts in papillary cystadenocarcinoma include, most often, cuboidal and columnar cells. Other cells types such as mucous, clear and oncocytic cells occasionally are noted as well [14].

Thus far, three cases of malignant transformation of sialadenoma papilliferum have been documented in the literature [4-6] (Table 1). Solomon et al. reported a soft palate sialadenoma papilliferum with lymph node metastasis, which later was re-interpreted as a mucoepidermoid carcinoma by others $[4,8]$. The case reported by Shimoda et al. [5] is a clearer example of malignancy associated with sialadenoma papilliferum. They described an epithelial-myoepithelial carcinoma containing a transition zone to adjacent sialadenoma papilliferum. Most recently, Ponniah [6] reported a case of sialadenoma papilliferum with carcinoma in situ in the exophytic component.

Our case demonstrates a mucoepidermoid carcinoma, apparently arising from a sialadenoma papilliferum. The superficial benign portion of the lesion retains the configuration of sialadenoma papilliferum. In comparison to the 
Table 1 Four reported cases of malignant transformation of sialadenoma papilliferum (SP) (1978-2009)

\begin{tabular}{llll}
\hline Authors & Year & Anatomical site & Associated malignancy \\
\hline Solomon et al. [4] & 1978 & Soft palate & Squamous cell carcinoma \\
Shimoda et al. [5] & 2004 & Junction between the soft and hard palate & Epithelial-myoepithelial carcinoma \\
Ponniah et al. [6] & 2007 & Floor of mouth & Carcinoma in situ in the squamous component of benign SP \\
Liu et al. (current case) & 2009 & Base of tongue & High-grade mucoepidermoid carcinoma
\end{tabular}

malignant transformation of a sialadenoma papilliferum reported by Shimoda et al. [5], in which the carcinoma component and the benign lesion are in close contact and share a transitional zone, the mucoepidermoid carcinoma in this case comprises the deeper portion of sialadenoma papilliferum while leaving the exophytic, papillary, surface structure intact. This case represents a rare example of malignant transformation of sialadenoma papilliferum, occurring in an unusual location for minor salivary gland tumors.

\section{References}

1. Abrams AM, Finck FM. Sialadenoma papilliferum: a previously unreported salivary gland tumor. Cancer. 1969;24:1057-63. doi: 10.1002/1097-0142(196911)24:5<1057::AID-CNCR2820240529> 3.0.CO;2-L.

2. Pimentel MT, Lopez Amado M, Garcia Sarandeses A. Recurrent sialadenoma papilliferum of the buccal mucosa. J Laryngol Otol. 1995;109:787-90. doi:10.1017/S0022215100131330.

3. Rennie JS, Macdonald DG, Critchlow HA. Sialadenoma papilliferum: a case report and review of the literature. Int J Oral Surg. 1984;13:452-4. doi:10.1016/S0300-9785(84)80074-5.

4. Solomon MP, Rosen Y, Alfonso A. Intraoral papillary squamous cell tumor of the soft palate with features of sialadenoma papilliferum-? malignant sialadenoma papilliferum. Cancer. 1978;42: 1859-69. doi:10.1002/1097-0142(197810)42:4<1859::AID-CNC R2820420425>3.0.CO;2-C.

5. Shimoda M, Kameyama K, Morinaga S, et al. Malignant transformation of sialadenoma papilliferum of the palate: a case report. Virchows Arch. 2004;445:641-6. doi:10.1007/s00428004-1091-4.

6. Ponniah I. A rare case of sialadenoma papilliferum with epithelial dysplasia and carcinoma in situ. Oral Surg Oral Med Oral Pathol Oral Radiol Endod. 2007;104:e27-9. doi:10.1016/j.tripleo.2006. 06.053 .

7. Brandwein MS, Ivanov K, Wallace DI, et al. Mucoepidermoid carcinoma: a clinicopathologic study of 80 patients with special reference to histological grading. Am J Surg Pathol. 2001;25: 835-45. doi:10.1097/00000478-200107000-00001.

8. Asahina I, Abe M. Sialadenoma papilliferum of the hard palate: a case report and review of literature. J Oral Maxillofac Surg. 1997;55:1000-3. doi:10.1016/S0278-2391(97)90078-1.

9. Eversole LR, Sabes WR. Minor salivary gland duct changes due to obstruction. Arch Otolaryngol. 1971;94:19-24.

10. Testa RF, Riva A, Puxeddu P. Ciliated cells in the main excretory duct of the submandibular gland in obstructive sialdenitis: a SEM and TEM study. Ultrastruct Pathol. 1987;11:1-10. doi:10.3109/ 01913128709023177.

11. Nakahata A, Deguchi H, Yanagawa T, et al. Coexpression of intermediate-sized filaments in sialadenoma papilliferum and other salivary gland neoplasms. J Oral Pathol Med. 1990;19:313-8. doi: 10.1111/j.1600-0714.1990.tb00851.x.

12. Ellis GL, Auclair PL. Mucoepidermoid carcinoma. In: Ellis GL, Auclair PL, Gnepp DR, editors. Surgical pathology of the salivary glands. Philadelphia, PA: W. B. Saunders company; 1991. p. $238-51$.

13. Chen KTK. Intraductal carcinoma of the oral cavity. Am J Surg Pathol. 2005;29:279. doi:10.1097/01.pas.0000149711.01559.b7. Letter.

14. Barnes EL, Eveson JW, Reichart P, Sidransky D, editors. Pathology and genetics of head and neck tumours. Kleihues P, Sobin LH, series eitors. World Health Organization classification of tumours. Lyon, France: IARC Press; 2005. 